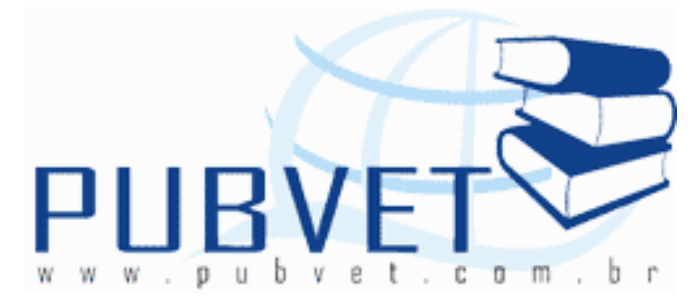

PUBVET, Publicações em Medicina Veterinária e Zootecnia.

\title{
Monta natural versus inseminação artificial em bovinos
}

\section{Gioto Ghiarone Terto e Sousa ${ }^{1}$; Nilton Andrade Magalhães ${ }^{2}$; Leopoldina Almeida Gomes²; Hélcio Santos Correia ${ }^{3}$; Severino Cavalcante de Sousa Júnior ${ }^{4}$; Karina Rodrigues Santos ${ }^{4}$; José Elivalto Campelo Guimarães ${ }^{5}$}

1 Pós-Graduando em Ciência Animal, Universidade Federal do Piauí, UFPI, Teresina, Piauí.

${ }^{2}$ Docentes, Instituto de Ensino Superior Múltiplo, IESM, Timon, Maranhão.

3 Médico Veterinário, Especialista em Bovinocultura Leiteira, TECFERTIL, Teresina.

${ }^{4}$ Docentes, Universidade Federal do Piauí, UFPI, Bom Jesus, Piauí.

${ }^{5}$ Docente, Universidade Federal do Piauí, UFPI, Teresina, Piauí.

\section{Resumo}

A busca por mudanças tecnológicas no setor agropecuário tem levado os países a montarem estratégias que proporcionem prosperidade e desenvolvimento no âmbito rural. A inseminação artificial tem sido rotina para a produção animal nos últimos 50 anos. Seu principal uso tem sido em bovinos leiteiros, associado aos testes de progênies e à utilização de touros geneticamente provados. Em países de clima temperado estes avanços técnicos refletiram em redução do custo de uma IA para o equivalente a de 50 a 60 litros de leite. Como a produção de leite por vaca dobrou nestes países nos últimos 30 anos, o custo da IA, em relação à produção de leite foi bastante 
SOUSA, G.G.T. et al. Monta natural versus inseminação artificial em bovinos. PUBVET, Londrina, V. 6, N. 35, Ed. 222, Art. 1473, 2012.

reduzido. A inseminação artificial quando utilizada para massificar a utilização de reprodutores geneticamente superiores, é a biotecnia de maior impacto para os programas de melhoramento animal. A interação cio e tempo para deposição do sêmen no trato reprodutivo feminino inseminação artificial ou monta natural são importantes para maximizar taxas de prenhes. Considerando-se que o ovócito é liberado do ovário de 10 a 14 horas após o final do cio, permanecendo fértil apenas por 6 a 12 horas, e o espermatozóide por 24 horas.

Palavras-chave: bovino de leite, bovino de corte, Biotecnologia da reprodução, reprodução.

\section{Natural versus artificial insemination in cattle}

\section{Abstract}

The search for technological change in the agricultural sector has led the countries to build strategies that provide prosperity and development in rural areas. Artificial insemination has been routine for livestock production in the last 50 years. Its main use has been in dairy cattle, associated with the tests of progenies and use genetically proven bulls. In temperate countries, these technical advances reflected in reduced cost of an AI to the equivalent of 50 to 60 liters of Milk. As the Milk production per cow doubled in these countries over the past 30 years, the cost of IA, in relation to Milk production was greatly reduced. Artificial insemination when used to commoditize the use of pure-bred breeding animals genetically superior, is the biotecnia of greater impact on animal breeding programs. Cio interaction and time for deposition of semen into the female reproductive tract artificial insemination or natural service are important to maximize rates of pregnant. Considering that the oocyte is released from the ovary of the $102: 0 \mathrm{pm}$ after the end of the cio, remaining fertile for only 6 to 12:0, and the sperm by 12:0 am.

Keywords: beef milk, beef breeding, reproduction biotechnology. 
SOUSA, G.G.T. et al. Monta natural versus inseminação artificial em bovinos. PUBVET, Londrina, V. 6, N. 35, Ed. 222, Art. 1473, 2012.

\section{Introdução}

A busca por mudanças tecnológicas no setor agropecuário tem levado os países a montarem estratégias que proporcionem prosperidade e desenvolvimento no âmbito rural. No Brasil, padrões tecnológicos estão sendo planejados com a finalidade de colocar os produtos agropecuários em nível da qualidade mundial. Na pecuária leiteira, medidas vêm sendo tomadas para que se crie um padrão único de produção com alta qualidade, produtividade e preços competitivos, tais como: uso de complementos alimentares, inseminação artificial, ordenha mecânica e granelização do leite (JANK, 1997).

Torres (1986), fala que, em se tratando de rebanhos inferiores, em variação desordenada, pode-se conseguir uma uniformização em nível elevado com o uso do sêmen de reprodutores de raça pura de boa qualidade através de uso da inseminação artificial. Para Marques (1988), á IA nos animais domésticos tem possibilitado um rápido melhoramento genético dos rebanhos porque, sobretudo democratizou a utilização de reprodutores de alta qualidade zootécnica. Permite que o médio e pequeno produtor programe a reprodução de seus rebanhos a base de sêmen de excelentes melhoradores, coisa que não seria possível se tivessem de adquirir o reprodutor por preços inacessíveis. Além disto, o reprodutor, quando utilizado em monta natural é bastante limitado por suas próprias condições fisiológicas.

A inseminação artificial tem sido rotina para a produção animal nos últimos 50 anos. Seu principal uso tem sido em bovinos leiteiros, associado aos testes de progênies e à utilização de touros geneticamente provados. A evolução da técnica a partir do uso de sêmen fresco, passando pelo uso de ampolas, palettes e mini-palettes, o aumento da eficiência na produção, armazenamento e distribuição de nitrogênio e dos métodos de descongelamento tornaram esse procedimento confiável (CUNNINGHAM, 1999).

Em países de clima temperado estes avanços técnicos refletiram em redução do custo de uma IA para o equivalente a de 50 a 60 litros de leite. Como a produção de leite por vaca dobrou nestes países nos últimos 30 anos, 
SOUSA, G.G.T. et al. Monta natural versus inseminação artificial em bovinos. PUBVET, Londrina, V. 6, N. 35, Ed. 222, Art. 1473, 2012.

o custo da IA, em relação à produção de leite foi bastante reduzido. Assim, a MN foi praticamente substituída pela forma artificial de inseminação nos rebanhos leiteiros comerciais da Europa e América do Norte. Por exemplo, na Dinamarca e na Holanda, $100 \%$ do rebanho leiteiro são inseminados artificialmente. Nos demais países, a utilização varia de 60 a 90\%. Em relação ao bovino de corte a situação é ao contrário em termos de lucros e ganhos genéticos (CUNNINGHAM, 1999).

A inseminação artificial quando utilizada para massificar a utilização de reprodutores geneticamente superiores, é a biotecnia de maior impacto para os programas de melhoramento animal. No Brasil, estimaram aumentos de 89,2 mil toneladas de leite e 22,2 mil de carne, num valor total de $U \$ 39$ milhões/ano, com o aumento de $30 \%$ do uso da biotecnia. Para que haja uma eficiência na produção leiteira são necessários dois fatores fundamentais: manejo e genética. Esses fatores, se trabalhados em conjunto, fazem a produção econômica de leite. A alimentação - um dos grandes gargalos da atividade - deve ser condizente com o nível genético dos animais, ou seja, às vezes o produtor trata vacas de alto potencial genético de produção com insuficiência em quantidade e qualidade de alimento, perdendo volume de leite (FERRAZ, 1996).

Martinez et al. (2004), fala que, atualmente, apesar do uso ainda de reprodutores em $\mathrm{MN}$, a inseminação artificial vem sendo utilizada cada vez mais em todos os países do mundo. Nos desenvolvidos como Estados Unidos, Canadá, França, Alemanha, Holanda, etc. Em que é utilizada na grande maioria dos rebanhos tem se promovido o melhoramento genético e alta produtividade. É como afirma Bergman (1999), o sucesso de uma biotecnia estará assegurado apenas se seus benefícios superarem seus custos.

A interação cio e tempo para deposição do sêmen no trato reprodutivo feminino (IA ou MN) são importantes para maximizar taxas de prenhes. Considerando-se que o ovócito é liberado do ovário de 10 a 14 horas após o final do cio, permanecendo fértil apenas por 6 a 12 horas, e o espermatozóide por 24 horas. A sincronia deste evento é vital para fecundação e 
SOUSA, G.G.T. et al. Monta natural versus inseminação artificial em bovinos. PUBVET, Londrina, V. 6, N. 35, Ed. 222, Art. 1473, 2012.

desenvolvimento embrionário. Neste sentido, maiores taxas de concepção são obtidas se a vaca for coberta ou inseminada em período hábil. Recomenda-se que vacas observadas em cio pela manhã sejam inseminadas à tarde e as observadas à tarde, na manhã do dia seguinte (HAFEZ, 1995; RAWSON, 1986).

Outro parâmetro considerado na avaliação do manejo reprodutivo é o número de serviço por concepção, ou seja, o número de inseminações ou montas realizadas até que o animal se torne gestante, intervalo entre partos e período de serviço. Este parâmetro fornece a avaliação da fertilidade da vaca e do touro, bem como a eficiência da IA. Número médio de serviço por concepção acima de 2,5 demonstra sérios problemas reprodutivos no rebanho. Valores inferiores a 1,8 são desejáveis, porém as metas visam atingir média de 1,4 a 1,6 serviços/concepção, refletindo assim a excelente fertilidade dos animais e um eficiente processo de inseminação artificial. A vaca não deve ser inseminada até uma hora após a ordenha, e a inseminação artificial deve ser feita num centro de manejo contendo tronco de contenção para o animal não se movimentar durante a inseminação artificial, facilitando o trabalho do inseminador (RAWSON, 1986).

\section{Inseminação artificial (IA)}

Segundo Mies Filho (1987), no melhoramento genético, a IA tem sido a grande ferramenta de disseminação maciça da genética aos mais tecnificados, e define: "a inseminação artificial é a operação que tem como fim introduzir o sêmen, puro ou diluído, nas vias genitais da fêmea em condições tais que permitam os espermatozoides encontrar o óvulo e fecundá-lo". A Inseminação Artificial (IA) é também conhecida como Técnica de Reprodução Assistida (TRA), termo pouco utilizado para bovinos. Acredita-se que teve seu início no ano de 1332, segundo a lenda, em equinos, pelos árabes (VANZIN, 2002).

Em 1779 foi realizado, segundo a história, a primeira Inseminação Artificial: foi quando o monge italiano Lázaro Spallanzani demonstrou ser 
SOUSA, G.G.T. et al. Monta natural versus inseminação artificial em bovinos. PUBVET, Londrina, V. 6, N. 35, Ed. 222, Art. 1473, 2012.

possível à fecundação de uma fêmea sem o contato direto com o macho, colheu sêmen de um cachorro através de excitação mecânica e o aplicou em uma cadela em cio, a qual veio a parir três filhotes (VANZIN, 2002).

Em 1912 russos encabeçados por Evan Ivanov deram a IA de animais domésticos, caráter de grande escala utilizando equinos. Era o nascimento de uma técnica que revolucionaria o campo da reprodução animal, sendo largamente utilizada em todo o mundo (VANZIN, 2002).

Em 1949 Polge, Smith e Parquer, pesquisadores ingleses, demonstraram que o espermatozóide podia ser conservado por um longo período de tempo a baixas temperaturas utilizando o nitrogênio líquido. Antes, o sêmen era conservado sob refrigeração $\left(5^{\circ} \mathrm{C}\right)$, e os espermatozoides tinham poucos dias de vida. Essa descoberta permitiu a sua conservação indefinidamente, dando maior difusão a IA e favorecendo, decisivamente, o incremento do comércio de sêmen e exaltando todas as vantagens que o procedimento proporciona (VANZIN, 2002).

De acordo com Vanzin (2002) muitos países inseminam quase a totalidade de seus rebanhos bovinos, calculando-se que no mundo mais de 90 milhões de vacas são anualmente inseminadas. As áreas que se sobressaem são: Europa com 33,3\%, Rússia 22,2\%, EUA 11,1\% e na América Latina 5,5\%. No Brasil registra-se a primeira IA em 1940 em caráter experimental; em 1950 a técnica foi utilizada em nível de campo, alcançando impulso comercial somente a partir de $1970 \mathrm{com}$ o aparecimento das primeiras empresas especializadas em TRA (VANZIN, 2002).

A inseminação artificial como biotecnia, passou a ser utilizada no mundo desde a década de 30, e no Brasil em 1940. Como exemplos podem-se citar a Dinamarca que teve um aumento considerável de 1940 quando inseminava apenas 25\% do seu rebanho leiteiro passando para 100\% em 1963 quando também Alemanha Ocidental inseminava 80\%, Japão 75\%, Holanda 60\%, Reino Unido 50\%, Estados Unidos 40\% e URSS 15\%. Em 1955 a França inseminava 24\% (ARAGÃO; PAES, 2008). 
SOUSA, G.G.T. et al. Monta natural versus inseminação artificial em bovinos. PUBVET, Londrina, V. 6, N. 35, Ed. 222, Art. 1473, 2012.

Aragão e Paes (2008) citam que os Estados Unidos, França, Dinamarca, Holanda e a Itália foram os primeiros países que praticaram a inseminação artificial em escala, num sistema de cooperativismo a partir da década de 40 , demonstrando sua viabilidade tecnológica, tendo em vista que, num sistema de produção organizado facilita a produção em escala, diminuindo custos e garantindo a inserção de produtores no mercado globalizado.

A pecuária leiteira encontra-se em fase de transição, passando de um modelo extrativista a uma pecuária competitiva, tendo, assim, que produzir de forma eficiente e com baixo custo. Fatores nutricionais, sanitários e problemas na identificação do cio contribuem para atraso no retorno à atividade ovariana pós-parto, maior período de serviço e de intervalo entre parto, redução no período de lactação e menor produção de bezerros por ano e durante sua vida útil. Assim, os custos de produção são elevados pela manutenção de animais com baixa produção no rebanho (ARAGÃO; PAES, 2008).

$\mathrm{Na}$ Inglaterra em estudos realizados por Esslemont e Peeler (1993) observou-se que, em 10.427 vacas de 63 rebanhos, houve prejuízos por diversos fatores, tais como: $7,3 \%$ foram abortados, $9,5 \%$ houve parto distócico, 31,7\% ocorrência de mastite e 50\% das vacas tiveram problemas na detecção de cio. O padrão ideal de eficiência reprodutiva consiste em se ter uma cria/ano, com intervalo de parto de 12 a 12,5 meses e período de lactação de 10 meses. Para se obter esse padrão é preciso que haja interação perfeita dos parâmetros genéticos, reprodutivos, sanitários e nutricionais. Dessa forma se faz necessário um monitoramento contínuo das metas definidas dentro dos parâmetros reprodutivos, solucionando problemas que comprometem essa eficiência.

No Brasil, Madalena et al. (1995; 1999), ao analisarem informações referentes à venda do sêmen importado de touros de raça leiteira, concluíram que as informações sobre o valor genético dos animais tiveram pouca influência sobre os preços do sêmen, os quais foram muito mais influenciados pelo parentesco dos touros com progenitores famosos e premiações ganhos. 
SOUSA, G.G.T. et al. Monta natural versus inseminação artificial em bovinos. PUBVET, Londrina, V. 6, N. 35, Ed. 222, Art. 1473, 2012.

Dias (1996) analisou as relações existentes entre os preços de sêmen e as principais informações promocionais ou técnicas disponíveis para os touros doadores e concluiu que, pelo menos, parte do mercado brasileiro de sêmen da raça Nelore já considera os aspectos genéticos no preço do sêmen, demonstrando certa evolução em relação aos levantamentos anteriores.

Como a IA é uma biotecnia madura e consagrada, futuro desdobramentos são dependentes dos aspectos econômicos na sua utilização. Novos métodos para deteç̧ão de cio ou as técnicas para a microencapsulação espermática, que reduz a importância do momento de inseminação (NEBEL et al., 1993) poderão assumir importância futura.

\section{Vantagens da inseminação artificial}

As vantagens da IA representadas pelo incremento do ganho genético nos programas de melhoramento está sustentada pela utilização de reprodutores de genética superior. Existem indicações na literatura que o progresso genético alcançado tem sido menor que o esperado, provavelmente devido á inclusão de outras características que não as produtivas de valor econômico nos processos seletivos (WILDER; VAN VLECK, 1988).

De acordo com Ferreira e Machado (2000) a inseminação artificial proporciona as seguintes vantagens:

> Possibilita o uso de sêmen de touros provados;

> Economiza na manutenção do rebanho pela ausência do reprodutor na propriedade;

> Possibilita baixo investimento em relação à aquisição de um bom reprodutor;

> Evita a transmissão de doenças pelo touro;

> Valoriza o rebanho pela qualidade dos animais;

$>\quad$ Permite o cruzamento alternado de raças diferentes;

> Possibilita a melhoria de certos caracteres desejáveis; 
SOUSA, G.G.T. et al. Monta natural versus inseminação artificial em bovinos. PUBVET, Londrina, V. 6, N. 35, Ed. 222, Art. 1473, 2012.

Facilita anotações e registros;

Estimula o produtor a aprimorar o manejo do rebanho.

Padronização do rebanho, controle de doenças sexualmente transmissíveis, ordenação do trabalho na fazenda, diminuição do custo de reposição de touros e etc. Mas, as principais vantagens estão ligadas ao processo de melhoramento genético e na obtenção de animais com maior potencial de produção e reprodução;

Aumento da produtividade a cada geração;

Evita doenças transmitidas durante a monta natural;

Prevenção de acidentes durante a cobertura, principalmente em caso de touros muito pesados;

Escolha do melhor touro para cada situação;

Evita acidentes com pessoal que lida com os touros, normalmente agressivo durante o cruzamento;

Armazenamento de sêmen de touros incapacitados pela ocorrência de acidente ou morte;

Aumento do número de descendentes por touro;

Permite ao criador cruzar suas fêmeas zebuínas com touros de raças europeias e vice-versa, através da utilização de sêmen desses touros. Sabemos que em muitas regiões touros europeus dificilmente se adaptam ao sistema de monta natural;

Além disso, é fácil entender que algum acidente poderia ocorrer durante a cobertura de uma vaca por um touro pesado;

Touros com problemas adquiridos e impossibilitados de efetuarem a monta, em razão de idade avançada, afecções nos cascos, fraturas, aderência de pênis, artroses, etc., poderão ser utilizados na inseminação artificial;

$>$ Evita acidentes com pessoal, os quais ocorrem comumente quando se trabalha com animais de temperamento agressivo;

A correção de deficiências no rebanho - através do acasalamento genético podemos corrigir várias deficiências do rebanho ao mesmo 
tempo, com a utilização de diversos touros em um mesmo trabalho de Inseminação Artificial. Desta forma, estaríamos atuando sobre as características individuais de cada matriz;

$>$ Escolha de reprodutores testados e na transmissão de características desejáveis ao rebanho leiteiro.

\section{Desvantagens da inseminação artificial}

Aspecto associado a falhas na IA e repetição do cio refere-se ao local de deposição correta do sêmen no corpo uterino, em que animais com alterações morfológicas em nível de cérvix possuem menores chances de fecundação (BARTH, 1993).

Em relação às desvantagens da IA, Ferreira e Machado (2000) apresenta as seguintes:

$\checkmark$ A IA exige tempo e mão de obra treinada e motivada para a observação do cio e para a realização da técnica;

$\checkmark$ Da mesma forma que a IA promove o melhoramento genético do rebanho e controle sanitário, pode ter o risco de a técnica disseminar na população uma expressão genética negativa ou mesmo doenças reprodutivas. Porém, se o material genético for adquirido de centrais registradas, o risco é insignificante;

$\checkmark$ Dificuldade de manter o sêmen armazenado devido à disponibilidade de nitrogênio líquido.

\section{Limitações da inseminação artificial}

Entretanto, uma das maiores causas da infertilidade associada a IA é a manipulação do sêmen. Geralmente, são considerados aspectos como coleta, diluição e congelamento do sêmen (BARTH, 1993). 
SOUSA, G.G.T. et al. Monta natural versus inseminação artificial em bovinos. PUBVET, Londrina, V. 6, N. 35, Ed. 222, Art. 1473, 2012.

Ferreira (2003) considera como limitações nos programas de IA os seguintes pontos:

$>\quad$ Necessita de pessoal habilitado;

> Necessita de assistência técnica periódica por técnico especializado;

$>$ Acarreta maior perda de cios;

> Aumenta gastos com mão de obra e equipamentos (botijão, pipeta, luvas e etc.).

Fatores que dependem do inseminador ressaltam-se acondicionamento, transporte e manipulação do sêmen no processo de IA.

\section{Monta natural (MN)}

A procriação natural ou monta natural è quando ocorre a reprodução entre o macho e fêmea realizando a cópula sem a interferência do homem (ALVAREZ, 2008). Fisiologicamente um touro possui a capacidade de realizar diariamente de três a cinco coberturas. Contudo, esse ritmo é reduzido consideravelmente ao longo do tempo. Geralmente, considera-se que um touro pode satisfazer as necessidades de um grupo de 30 a 50 vacas durante um período de monta de aproximadamente quatro meses. Nessa condição, o touro pode passar de períodos de excessiva atividade sexual a longos períodos improdutivos diminuindo de forma significativa o número de nascimentos do rebanho (ALVAREZ, 2008).

O número de espermatozoides liberado em um ejaculado de touro (aproximadamente cinco bilhões) é muito superior às necessidades da fecundação. Com efeito, esse processo pode ser realizado com eficiência utilizando unicamente três milhões de espermatozoides (às vezes menos) quando colocados diretamente no útero aumentando de forma significativa o aproveitamento espermático. Na prática, e por medida de segurança, uma dose de sêmen congelado contém aproximadamente 20 milhões. Assim, diluído 
em um tampão adequado, um único ejaculado fracionado é capaz de fecundar algumas centenas de fêmeas.

A criopreservação do sêmen possibilita que todas as suas características sejam mantidas indefinidamente, não sendo necessário utilizar o sêmen fresco no período imediatamente pós-coleta, permitindo planificar a frequência de coletas (entre duas e seis coletas de sêmen semanais) e aperfeiçoar os estoques disponíveis aos produtores. Tecnicamente, é possível armazenar mais de 100.000 doses de sêmen por touro (ALVAREZ, 2008).

\section{Vantagens da monta natural}

* Possibilita melhor aproveitamento de cios;

* Economiza mão de obra (FERREIRA, 2003).

\section{Desvantagens da monta natural}

* Dificulta a anotação do dia de cobertura;

* Diminui a vida útil do touro pelo excesso de montas;

* Aumenta a possibilidade de acidente com o touro;

* Favorece a transmissão de doenças da reprodução, como: viroses, triconomose e campilobacteriose (FERREIRA, 2003).

A Embrapa, em colaboração com a Associação Brasileira de Inseminação Artificial (ASBIA), elaborou uma planilha para gado de leite em que o próprio produtor pode avaliar o custo da obtenção de uma fêmea por monta natural MN ou IA (MARTINEZ et al., 2004). O aplicativo encontra-se dividido em planilhas destinadas à estimativa dos custos da IA e MN. Nas planilhas são 
SOUSA, G.G.T. et al. Monta natural versus inseminação artificial em bovinos. PUBVET, Londrina, V. 6, N. 35, Ed. 222, Art. 1473, 2012.

apresentadas três possibilidades ou alternativas de simulação, permitindo a introdução de dados em diferentes cenários (número de fêmeas, a relação reprodutor/fêmea, a taxa de concepção e a relação doses de sêmen/concepção etc). Embora os custos operacionais da IA, em alguns casos sejam superiores à $M N$, o resultado final será sempre favorável a $I A$, devido ao ganho genético incorporado ao rebanho (ALVAREZ, 2008).

\section{Considerações finais}

De acordo com o estudo realizado as duas biotecnicas são eficientes, resaltando suas vantagens e desvantagens juntamente com suas respectivas limitações. A monta natural se torna mais viável para pequenos e ou ate médios fazendeiros ficando assim a inseminação artificial para alta produção de carne e leite tendo em vista que para se produzir em alta escala e com maior tecnificação nas propriedades precisa-se evoluir para poder se torna competitivo dentro do mercado e obter um melhor desempenho do seu rebanho.

\section{Referências bibliográficas}

ALVAREZ, R. H. Considerações sobre o uso da inseminação artificial em bovinos. 2008. Artigo em Hipertexto.

Disponível em:<http://www.infobibos.com/Artigos/2008_1/Inseminacao/index.htm>. Acesso em: $5 / 6 / 2010$.

AMARAL, T. B.; COSTA, F.P, CORRÊA, E. S.; Inseminação artificial ou monta natural com o uso de touros melhoradores: análise econômica. In: 40a REUINIÃO DA SOCIEDADE BRAZILEIRA DE ZOOTECNIA (Anais, CD-ROM), Santa Maria, RS, 2003.

ARAGÃO, J. L.; PAES, M. S. Área biotecnologia. In: CONGRESSO BRASILEIRO DE MEDICINA VETERINARIA, 10., 2008, Gramado. Anais eletrônicos... Gramado, 2008. $35^{\circ}$ CONBRAVET, 2008.

Disponível em:

http://www.sovergs.com.br/conbravet2008/anais/cd/lista_area_12.htm>. Acesso em: 15 jun. 2010.

BERGMANN, J. A. G., PENNA, V. M., The impact of new biotechnology on animal breeding programs. Arq. Fac. Vet. UFRGS, 27(1): 108-129, 1999 (supl.).

BARTH, A. D. Factor's affecting fertility with artificial insemination. Vet. Clin. North Amer.:

Food Anim. Prac., v. 9, n. 2, p. 275-89., 1993. 
CUNNINGHAM, E. P. The application of biotechnologies to enhance animal production in defferent farming systems. Livest. Prod. Scientific., 58:1-24, 1999.

DIAS, F. M. G. N. Fatores que influenciam o preço do sêmen de Nelore. Anais. 1 Simpósio Nacional de Melhoramento Animal, Ribeirão Preto, Sociedade Brasileira de Melhoramento Animal, Ribeirão Preto, 209-212, 1996.

ESSLEMONT, R. J.; PEELER, E. J. The scope for raising margins in dairy herds by improving fertility and health. Br. Vet. J. , v.149, n.6, p.537-547, 1993.

FERREIRA, A. M. Causas de repetição de cios em bovinos: uma revisão. Coronel Pacheco - MG, Embrapa CNPGL, 1985. 48 p. (Embrapa - CNPGL, Documentos, 17).

FERREIRA, A. M., Monta Natural e Monta Natural Controlada. Disponível em: http://www.agencia.cnptia.embrapa.br. 2003. Acesso em: 30 mai. 2010.

FERREIRA, M. B. D.; MOURÃO, G. B.; LOPES, B. C. Duração da gestação em zebuínos inseminados com touros da raça holandesa. In: XV Encontro de Pesquisa, Anais..., 1996., p. 143.

; FERREIRA, A. de M.; MACHADO, M. A. Biotecnologia na pecuária: tecnologias reprodutivas. Informe Agropecuário, Belo Horizonte, v. 21, n.204, p. 79-88, maio/jun. 2000.

FERRAZ, J. B. S. Impacto econômico na pecuária de leite e de corte do Brasil, com o aumento da utilização da inseminação artificial. Revista Brasileira de Reprodução Animal., 20:9598, 1996.

HAFEZ, E. S. E. Inseminação artificial. In: HAFEZ, E. S. E. Reprodução animal. 6a. Ed. São Paulo: Manole, 1995. 582 p., Cap.20., p.431-447.

HAFEZ, E. S. E. Inseminação artificial. In: HAFEZ, E. S. E. Reprodução animal. 7a. Ed. São Paulo: Manole, 2004.

JANK, S. M. Programa de estudo dos negócios do sistema agroindustrial: Competitividade do sistema agroindustrial do leite, São Paulo: USP, 1997. 28p.

MARQUES, D. C. Criação de Bovinos. 6a. Ed. São Paulo: Nobel, 1988.

MARTINEZ, M. L.; YAMAGUCHI, L. C. T.; VERNEQUE, R. S. Aplicativo para cálculo do custo da Monta Natural e da Inseminação Artificial em bovinos. Juiz de Fora: Embrapa/ASBIA, 2004, 12 P.

MADAlenA, F. E., VERNEQUE, R. S., TEODORO, R. L. Fatores que influenciam o preço do sêmen importado. Revista Brasileira de Genética., 8:377-384, 1995.

MADAlenA, F. E., MADUREIRA, A. P., PENNA, V. M., TURRA, E. M. Fatores que afetam o preço do sêmen bovino das raças Nelore e Gir Leiteiro. Revista Brasileira de Zootecnia. 1999.

MIES FILHO, A. Inseminação Artificial. 6a. Ed. Porto Alegre: Sulina, 1987.

MOURA. J. F. P. Índices zootécnicos e econômicos relativos à exploração de bovinos zebus em uma propriedade no semiárido paraibano. Fevereiro, 2005. 
NEBEL, R. L., VISHWANATH, R., MCMILLAN, W. H., SAACKE, R. G. Microencapsulation of bovine spermatozoa for use in artificial insemination: a review. Reprodução Fertilidade. Dev., 5:701-712. 1993.

RAWSON, C. L. Reproductive management of small dairy farms. In: MORROW, D.A Current therapy in Theriogenology. S/ed. Philadelphia, PA: W. B. Saunders Company, 1986. 1143 p., p. 390-394.

SOUZA. D. A. Departamento técnico da Emater - MG. Disponível em:<http://www.emater.mg.gov.br/2008/site_emater/Serv_Prod/Livraria/Agrida/ técnicas_agrop...>. Acesso em: 17/09/2010.

TORRES, A. di P. Melhoramento dos Rebanhos. 4. Ed. São Paulo: Nobel, 1986.

VANZIN, I. Repav- inseminação artificial e manejo reprodutivo em bovinos. [S.I]: 2002. Disponível In: <http://www.inseminacaoartificial.com.br/index.htm>. Acesso em: 05 jun.2010, 14h10min.

WILDER, J. S.; VAN VLECK, L. D. Relative economic values assigned to milk, fat test and type in pricing of bull's semen. Jornal Dairy Sciense., 71:492-497, 1988. 